\title{
CORRIGENDUM
}

\section{Abdominal functional electrical stimulation to improve respiratory function after spinal cord injury: a systematic review and meta-analysis}

EJ McCaughey, RJ Borotkanics, H Gollee, RJ Folz and AJ McLachlan

Spinal Cord (2016) 54, 754; doi:10.1038/sc.2016.70

Correction to: Spinal Cord (2016) 54, 628-639; doi:10.1038/ The authors apologise for any inconvenience caused. sc.2016.31; published online 12 April 2016

Since the publication of this article, the authors have noticed that the author name 'RJ Borotkanics' was spelled incorrectly. The PDF and online versions have been amended. 